\title{
Presynaptic Defects Underlying Impaired Learning and Memory Function in Lipoprotein Lipase-Deficient Mice
}

\author{
Xunde Xian, ${ }^{1 *}$ Tingting Liu, ${ }^{2 *}$ Jia Yu,${ }^{2 *}$ Yuhui Wang, ${ }^{1}$ Yifei Miao, ${ }^{2}$ Jianjun Zhang, ${ }^{3}$ Yan $Y u,{ }^{2}$ Colin Ross, ${ }^{4}$ \\ Joanna M. Karasinska, ${ }^{4}$ Michael R. Hayden, ${ }^{4}$ George Liu, ${ }^{1}$ and Dehua Chui ${ }^{2}$ \\ ${ }^{1}$ Institute of Cardiovascular Sciences and Key Laboratory of Molecular Cardiovascular Sciences and ${ }^{2}$ Neuroscience Research Institute and Department of \\ Neurobiology, Key Laboratory for Neuroscience, Ministry of Education, Key Laboratory for Neuroscience, Ministry of Public Health, Health Science Center, \\ Peking University, Beijing 100191, China, ${ }^{3}$ Institute of Materia Medica, Chinese Academy of Medical Sciences, Beijing 100050, China, and ${ }^{4}$ Department of \\ Medical Genetics, Centre for Molecular Medicine and Therapeutics, University of British Columbia, Vancouver, British Columbia, Canada V5T 4H4
}

Lipoprotein lipase (LPL) is predominantly expressed in adipose and muscle where it plays a crucial role in the metabolism of triglyceriderich plasma lipoproteins. LPL is also expressed in the brain with highest levels found in the pyramidal cells of the hippocampus, suggesting a possible role for LPL in the regulation of cognitive function. However, very little is currently known about the specific role of LPL in the brain. We have generated a mouse model of LPL deficiency which was rescued from neonatal lethality by somatic gene transfer. These mice show no exogenous and endogenous LPL expression in the brain. To study the role of LPL in learning and memory, the performance of LPL-deficient mice was tested in two cognitive tests. In a water maze test, LPL-deficient mice exhibited increased latency to escape platform and increased mistake frequency. Decreased latency to platform in the step-down inhibitory avoidance test was observed, consistent with impaired learning and memory in these mice. Transmission electron microscopy revealed a significant decrease in the number of presynaptic vesicles in the hippocampus of LPL-deficient mice. The levels of the presynaptic marker synaptophysin were also reduced in the hippocampus, whereas postsynaptic marker postsynaptic density protein 95 levels remained unchanged in LPL-deficient mice. Theses findings indicate that LPL plays an important role in learning and memory function possibly by influencing presynaptic function.

\section{Introduction}

Lipoprotein lipase (LPL) is a key enzyme hydrolyzing plasma triglyceride carried in very low density lipoproteins (VLDLs) and chylomicrons (CMs). The major sites of expression of LPL are in adipose tissue and skeletal muscle (Eckel, 1989; Goldberg, 1996; Preiss-Landl et al., 2002). Prior studies revealed the presence of LPL mRNA and activity in the brain in several mammalian species, including rat, mouse, and rabbit (Brecher and Kuan, 1979; Goldberg et al., 1989; Yacoub et al., 1990). The highest expression of LPL was found in the hippocampus, where LPL mRNA and protein levels were $\sim 2$-fold higher than other brain regions.

\footnotetext{
Received Jan. 18, 2009; accepted March 1, 2009.

This project was supported in part by the National Natural Science Foundation of China (NSFC; Grants No. 30570533 and No. 30670414) and the National High Technology Research and Development Program of China (973 Program No. 2006CB500705 and 863 Program No. 0060102A4031; to D.C.), Major National Basic Research Program of the People's Republic of China (G2006CD503801), a grant of Sino-Canada joint research fund from the NSFC and Canadian Institutes of Health Research (M.R.H., G.L.), and a grant from the National Natural Science Foundation of People's Republic of China (No. 30821001; to G.L.). M.R.H. holds a Canada Research Chair in Human Genetics and Molecular Medicine. J.M.K. is a recipient of postdoctoral awards from the Heart and Stroke Foundation of Canada and the Michael Smith Foundation for Health Research.

*X.X., T.L., and J.Y. contributed equally to this work.

Correspondence should be addressed to either Dr. George Liu or Dr. Dehua Chui, Peking University Health Science Center, 38 Xueyuan Road, Hai Dian District, Beijing 100191, China, E-mail: vangeorgeliu@gmail.com or dchui@bjmu.edu.cn.

X. Xian's present address: Department of Molecular Genetics, University of Texas Southwestern Medical Center at Dallas, 5323 Harry Hines Boulevard, Dallas, TX 75390-9046.

DOI:10.1523/JNEUROSCI.0297-09.2009

Copyright $\odot 2009$ Society for Neuroscience $\quad$ 0270-6474/09/294681-05\$15.00/0
}

Within the hippocampus, CA1 and CA3 pyramidal neurons have been shown to have the most abundant LPL mRNA by in situ hybridization (Yacoub et al., 1990).

Neuronal cell lines expressing high levels of active LPL display significant neurite extensions in the presence of VLDL and higher survival rate when exposed to oxidized VLDL (Paradis et al., 2003, 2004). However, considering that the enzymatic function of LPL is to hydrolyze triglyceride (TG) in VLDLs and CMs, and that only high density lipoprotein (HDL)-like lipoproteins circulate in the brain, it is likely that LPL has a nonenzymatic function in the brain parenchyma (Demeester et al., 2000; Koch et al., 2001).

We sought to investigate the role of LPL in the brain, specifically its role in learning and memory. Behavioral studies have not been performed in adult LPL gene-targeted mice because of neonatal lethality (Sattler et al., 1996). By rescuing through somatic gene transfer of a beneficial mutant form of LPL, we have generated viable adult LPL-deficient mice (Ross et al., 2005). In the present study, we report a significant impairment in learning and memory in LPL-deficient animals and demonstrate alterations in presynaptic morphology. Our findings demonstrate that LPL plays a role in cognitive function in the CNS.

\section{Materials and Methods}

Detailed methods can be found in online supplemental Methods, available at www.jneurosci.org as supplemental material. LPL-deficient mice with C57BL/6J background were rescued by intramuscular administra- 
tion of an adenoviral vector coding a human LPL mutant, LPL ${ }^{\text {S447X }}$. Learning and memory were examined by both a water maze and stepdown passive avoidance test. Sections of the brain were examined by Nissl staining for morphological evaluation and also stained by immunofluorescence with antibodies against synaptophysin and neurofilaments (Chui et al., 1999). Quantification was performed by image analysis. Ultrastructure of synapses in hippocampus was examined by transmission electron microscopy. Vitamin E content in plasma and brain was assayed chemically. Western blot of neurofilaments, synaptophysin, and postsynaptic density protein 95 (PSD-95) were done with corresponding antibodies and quantitated against glyceraldehyde-3-phosphate dehydrogenase (GAPDH). For evaluation of neuronal apoptosis, brains were either stained by TUNEL or assayed by a DNA ladder experiment. Expression of mouse and human LPL in the brain was detected by real-time reverse transcriptase (RT)-PCR. The results were expressed as mean \pm SEM. The statistical significance of differences between the two groups was evaluated with unpaired Student's $t$ test, and $p$ values $<0.05$ were regarded as significant.

\section{Results}

We have previously shown that LPL activity in plasma of adult LPL-deficient mice was almost undetectable ( $<7 \%$ of normal) (Zhang et al., 2008). As the result, plasma TG levels in these mice were 40 times higher than wild-type (WT) control mice $(5658.3 \pm 1250$ and $137.8 \pm 30.3 \mathrm{mg} / \mathrm{dl}, p<0.001)$ (supplemental Table 1, available at www.jneurosci.org as supplemental material). Although plasma total cholesterol increased nearly fourfold, the HDL-cholesterol was significantly decreased in these LPL-deficient mice $(278.1 \pm 58.7$ vs $65.2 \pm 7.1$ and $4.2 \pm 0.3$ vs $42.1 \pm 2.3 \mathrm{mg} / \mathrm{dl} ; p<0.01$, respectively). There was no significant difference in glucose levels between the two groups of mice, but the body weight of LPL-deficient mice was 14\% lower than WT (supplemental Table 1, available at www.jneurosci.org as supplemental material).

To rule out the potential presence of human LPL expression in the brain as the result of intramuscular adenoviral gene delivery, Human LPL mRNA and protein from brains were assessed by RT-PCR and immunofluorescence with a monoclonal antibody against human LPL. As shown in supplemental Figure 1, available at www.jneurosci.org as supplemental material, by RT-PCR, a single 573 bp band corresponding to mouse LPL was easily seen in WT brain (supplemental Fig. $1 \mathrm{~A}$, left three lanes, available at www.jneurosci.org as supplemental material) but not in LPL-deficient mice (supplemental Fig. $1 A$, right three lanes, available at www.jneurosci.org as supplemental material). Human LPL mRNA and protein were undetectable in the brains in both LPL-deficient and WT mice (supplemental Fig. 1B, C, available at www.jneurosci.org as supplemental material).

Hippocampus-dependent learning and memory of LPLdeficient mice were studied in both water maze performance and step-down passive avoidance test. In water maze test, during training sessions (day 1 and 2), LPL-deficient mice spent significantly longer time than WT mice to find the terminal escape platform ( $147.9 \pm 14.1$ vs $67.7 \pm 28.7$ and $121.0 \pm 18.6$ vs $71.6 \pm$ 9.7 s; $p<0.05$, respectively) (Fig. $1 A$ ). No differences in the number of entries into the nonexit arms were found on day 1 of training between the genotypes ( $4.5 \pm 1.1$ vs $3.0 \pm 0.4 ; p=0.24$ ). The number of no-exit arm entries was, however, significantly increased in LPL-deficient mice on day 2 of training $(5.0 \pm 0.5 \mathrm{vs}$ $2.1 \pm 0.4 ; p<0.001)$. From day 3 to day 7 , both the latency to escape platform and the frequency of entries into the no-exit arms in LPL-deficient mice were significantly increased than in WT mice. There was a significant correlation between the latency to escape platform and the error numbers (Fig. $1 A-C$ ). No changes in swim speeds were observed on any of the days of the training period ( $85.66 \pm 10.28$ vs $87.56 \pm 8.620 \mathrm{~mm} / \mathrm{s} ; p=0.89)$. This suggests that the increase in latency to platform is most likely attributable to an impairment in navigational strategy in LPLdeficient mice. In fact, the number of entries into the nonexit arms which did not include the escape platform was increased in LPL-deficient mice (Fig. $1 \mathrm{~B}$ ). We further used step-down inhibitory avoidance task to study the role of LPL in learning and memory. As shown in Figure $1 D$, a significant decrease in the latency to step-down in LPL-deficient mice was observed in the training trial $(18.5 \pm 1.5$ vs $34.7 \pm 1.4 \mathrm{~s} ; p<0.001)$. Similarly, a shortened retention time was observed in LPL-deficient mice $(639.8 \pm 140.9$ vs $1467 \pm 221.4 s ; p<0.01)$.

To search for the structural basis underlying the behavioral deficits associated with cognitive functions in LPL-deficient mice, we examined the neuronal counts, synaptic structure, and evidence for apoptosis in the hippocampus. There was no significant difference in neuronal numbers, subcellular structures, and neuronal apoptosis, as determined via light microscopic and transmission electron microscopy image analysis, and TUNEL plus DNA ladder assay (supplemental Figs. 2, 3, available at www.jneurosci.org as supplemental material). However, a severe depletion of synaptic vesicles in presynaptic terminals of LPLdeficient mice was observed (Fig. 2). Quantitatively, the numbers of total vesicles per terminal (TV) and docked vesicles (DV; defined as the vesicles within $50 \mathrm{~nm}$ from the plasma membrane in an active zone) were significantly reduced (TV: $15.6 \pm 1.2$ vs $29.2 \pm 3.5, p<0.001$; DV: $2.55 \pm 0.23$ vs $4.45 \pm 0.28, p<0.001$, respectively) when compared with controls. The number of vesicles per terminal (DV per micrometer) and docked vesicles per 


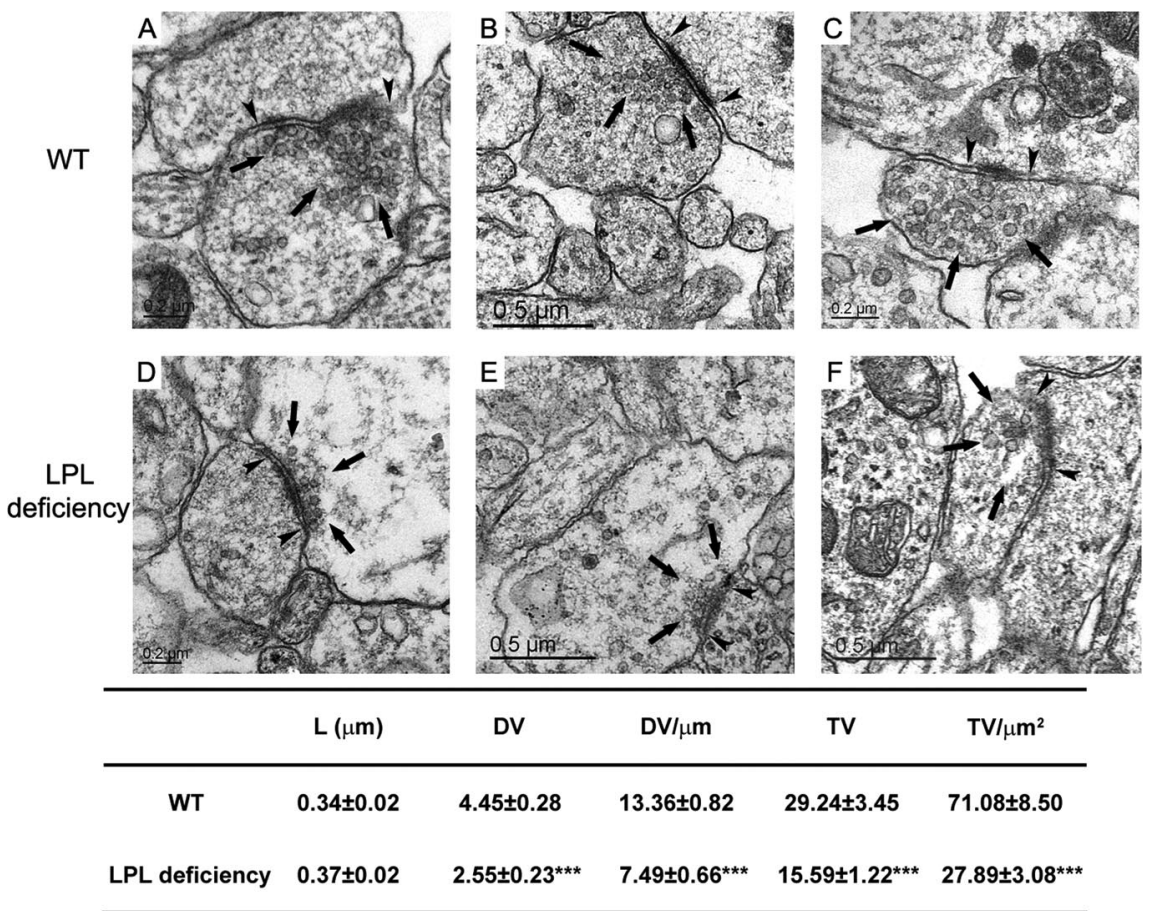

Figure 2. Ultrastrucural changes of synapses from WT and LPL-deficient neonatal mice detected by transmission electron microscopy. Synaptic vesicles within the presynaptic part are highlighted by arrows; the edges of the active zone/postsynaptic density complexes are marked by arrowheads. $\boldsymbol{A}-\boldsymbol{C}$ are representative photos showing the total and docked synaptic vesicles in the hippocampal terminals of WT mice, whereas $\boldsymbol{D}-\boldsymbol{F}$ are those of LPL-deficient ones. The table below shows the morphological analysis of synapses in CA3 regions of hippocampi from WT and LPL-deficient mice. L, Active zone length ( $\mu \mathrm{m})$; DV, number of docked vesicles per active zone; DV/ $\mu \mathrm{m}$, number of docked vesicles per micrometer of active zone length; TV, total vesicle number per terminal; TV $/ \mu \mathrm{m}^{2}$, total vesicle number per micrometer square of synapse area. Numbers are mean $\pm \mathrm{SEM} ; 30$ synapses from each mouse were analyzed in WT group $(n=4) ; 50$ synapses from each mouse were analyzed in LPL deficiency group $(n=4)$. *** $p<0.001$.
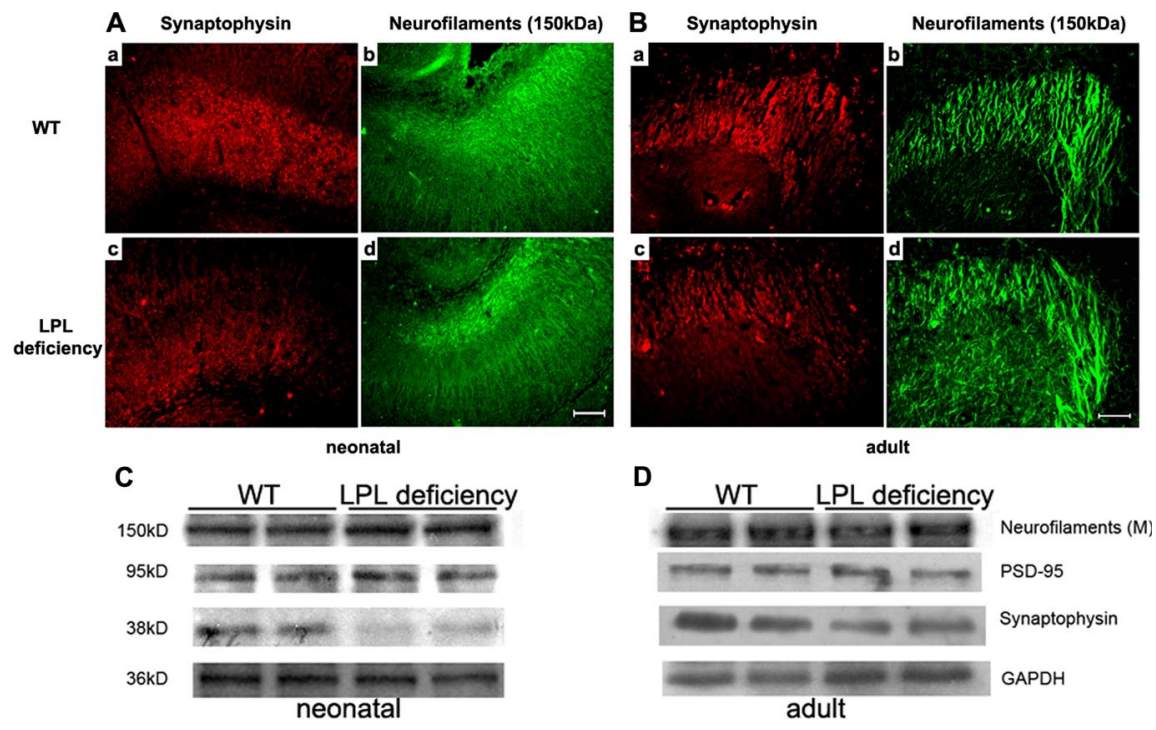

Figure 3. Immunofluorescence of presynaptic vesicles and neurofilaments in hippocampi of LPL-deficient and WT mice. Paraffin-embedded sections were immunostained and quantitated for presynaptic vesicle marker synaptophysin and cytoskeleton marker neurofilaments M. $\boldsymbol{A}$, From neonatal mice ( $n=5$ for WT and $n=3$ for LPL deficiency); $\boldsymbol{B}$, from adult mice $(n=6$ for WT and $n=3$ for LPL deficiency). Scale bar, $50 \mu \mathrm{m}$. Western blotting detection of synaptophysin, PSD-95, and neurofilament M (150 kDa) levels in the hippocampus from WT and LPL-deficient mice. C, D, The hippocampal protein homogenates of neonatal (C) and adult $(\boldsymbol{D})$ mice were subjected to SDS-PAGE, electrotransferred to PVDF membranes, and detected with antibodies against neurofilaments, PSD-95, and synaptophysin. Quantitation of blots was done by image analysis against GAPDH. square micrometer of synapse area (TV per micrometer square) were all reduced $(p<0.001)$ accordingly.

Immunofluorescence and Western blotting were used to examine the levels of synaptic markers including presynaptic synaptophysin, postsynaptic PSD-95 as well as neurofilament-M. In immunohistochemical analysis, synaptophysin levels in the hippocampus of both adult $(20 \%$ of control; $p<0.001)$ and neonatal $(24 \%$ of control; $p<0.001)$ LPL-deficient mice were significantly decreased, whereas neurofilament-M levels were similar, compared with WT mice (Fig. $3 A, B$ ). Western blotting showed similar results with significant reduction of synaptophysin levels in the hippocampus of both neonatal ( $33 \%$ of control; $n=4$ for both WT and LPL deficiency; $p<0.001$ ) and adult ( $58 \%$ of control; $n=4$ for both WT and LPL deficiency; $p<0.01)$ LPL-deficient mice, whereas no change of neurofilament-M or PSD-95 was observed, as shown in Figure 3, $C$ and $D$.

To detect the effect of LPL on brain lipids, we analyzed vitamin $\mathrm{E}$ content in plasma and brains in LPL-deficient and WT mice. Marked accumulation of vitamin $\mathrm{E}$ in plasma was noticed in adult LPLdeficient mice (Fig. 4A) (64.2 \pm 9.7 vs $4.5 \pm 0.3 \mu \mathrm{g} / \mathrm{ml} ; p<0.001)$, whereas the levels of vitamin $\mathrm{E}$ in the hippocampus were dramatically decreased (Fig. 4B) $(1.4 \pm 0.2$ vs $9.2 \pm 2.7 \mathrm{ng} / \mathrm{mg} ; p<0.001)$. The contents of vitamin $\mathrm{E}$ in the brains of the LPL-deficient fetus were also significantly lower than in WT fetus (Fig. 4C) $(1.19 \pm 0.17$ vs $3.05 \pm 1.05 \mathrm{ng} / \mathrm{mg} ; p<$ $0.05)$. These findings indicated a possible role of LPL in the transport of vitamin $\mathrm{E}$ from the periphery to the CNS.

\section{Discussion}

The current study was undertaken to investigate the role of LPL in the CNS in vivo. Specifically, in the present study, we have used viable adult LPL-deficient mice and demonstrated that these mice display impaired hippocampus-dependent learning and memory, indicating an important role of LPL in cognitive function. In search for the structural basis for such dysfunction, no obvious difference in neuronal counts or neuronal apoptosis could be observed. However, ultrastructural analysis revealed severe depletion of synaptic vesicles at presynaptic terminals of hippocampal neurons in LPL-deficient mice. Consistent with this, decreased levels of the presynaptic marker synaptophysin were also detected.

The reduction of synaptophysin and 
synaptic vesicles in the hippocampus in LPL-deficient mice could be involved in the impairment of learning and memory function, as demonstrated in other animal models and in human studies (Bamji et al., 2003; Tanemura et al., 2006). Neuronal synapses are essential for memory formation and maintenance. Neurotransmitter release at neuronal synapses is mediated by the synaptic vesicle through fusion and exocytosis at active zones (Sudhof, 2004; Rohrbough and Broadie, 2005). Recent discoveries have made researchers focus on a wider consideration of synaptic vesicle cycle lipids and lipid-based regulatory mechanisms rather than only on protein mechanism (Rohrbough and Broadie,

2005). It is shown that some kinds of lipids interact with lipidbinding proteins and have effects on the synaptic vesicle cycle. In the process of vesicle exocytosis, phosphatidylinositol-4,5bisphosphate-DAG-mediated signaling and lipid-protein interactions have regulating effects in several synaptic vesicle cycle stages, such as vesicle priming and fusion (Martin, 2001; Wenk and De Camilli, 2004). Also, cholesterol is enriched in secretory and synaptic vesicles as well as the exocytic domains of neurosecretory cell plasma membranes (Deutsch and Kelly, 1981; Michaelson et al., 1983; Benfenati et al., 1989; Lang et al., 2001). Cholesterol binds to synaptophysin and modulates the interaction with synaptobrevin, which is one of the essential vesicular SNARE proteins, and this function of cholesterol helps vesicle trafficking (Thiele et al., 2000; Mitter et al., 2003).

Although the function of LPL in the brain is not clearly understood, several previous in vitro studies have suggested several possible functions for LPL in the CNS. Paradis et al. (2004) reported that active LPL promoted VLDL-stimulated differentiation of Neuro-2A cells, indicating the enzymatic activity of LPL may play a role in the CNS, although VLDL is normally not present in CSF. LPL was also found to regulate the uptake of vitamin $\mathrm{E}$ from chylomicrons in both patients with LPL deficiency (Traber et al., 1992) and LPL transgenic mice (Sattler et al., 1996). Indeed, in cultured porcine brain capillary endothelial cells, LPL is found to be crucial for transport of vitamin E across the blood-brain barrier (BBB). Moreover, a 25\% reduction in the cerebral concentration of vitamin $\mathrm{E}$ was observed in LPLdeficient neonates (Goti et al., 2002). Others used dietary vitamin E-deficient Wistar rats and found the synapse-to-neuron ratio decreased by $30 \%$, and both the numerical density of the synapses and total synaptic area decreased significantly as well, suggesting that decreases in vitamin $\mathrm{E}$ intake could significantly affect the structural dynamics of hippocampal cholinergic synapses (Fattoretti et al., 1995). By using fluorescent and EPR spin probing techniques in investigation of rat brain synaptosomal membranes, Erin et al. (1986) observed stabilization of synaptosomal membranes by $\alpha$-tocopherol, suggesting a possible mechanism for the effect of vitamin $\mathrm{E}$ on biological membranes. In addition, synaptophysin, one of the presynaptic vesicle membrane proteins, was significantly increased in the brains of rats treated with vitamin E (Ferri et al., 2006). In addition, the study of behavioral changes in rats with vitamin $\mathrm{E}$ deprivation showed the slightly impaired spatial concept formation and significant impaired relearning ability in these animals (Sarter and van der Linde, 1987), whereas the research in older persons demonstrated a significant association of vitamin $\mathrm{E}$ intake, from foods or supplements, with
B

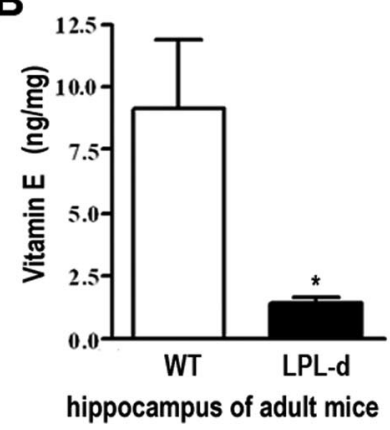

C

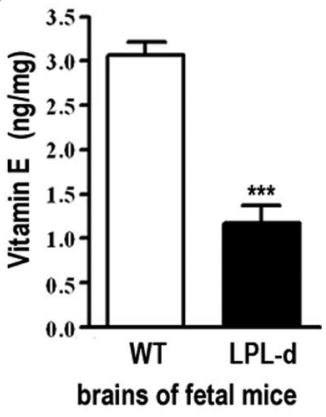

less cognitive decline with age (Morris et al., 2002), indicating the possible relation between low level of vitamin $\mathrm{E}$ in brain and memory impairment. In the present study, we observed a sixfold decrease in vitamin E levels in the hippocampus of adult LPLdeficient mice and a $60 \%$ reduction in vitamin $\mathrm{E}$ in cerebral regions of the LPL-deficient fetus, as well as a significant accumulation of vitamin $\mathrm{E}$ in the plasma.

Thus, impaired transport of vitamin $\mathrm{E}$ across the $\mathrm{BBB}$ in these LPL-deficient mice is most likely responsible for the observed presynaptic vesicle reduction and subsequent memory impairment in LPL-deficient mice. Further investigation in this area is certainly warranted to explore the precise mechanism(s) in details.

\section{References}

Bamji SX, Shimazu K, Kimes N, Huelsken J, Birchmeier W, Lu B, Reichardt LF (2003) Role of beta-catenin in synaptic vesicle localization and presynaptic assembly. Neuron 40:719-731.

Benfenati F, Greengard P, Brunner J, Bähler M (1989) Electrostatic and hydrophobic interactions of synapsin I and synapsin I fragments with phospholipid bilayers. J Cell Biol 108:1851-1862.

Brecher P, Kuan HT (1979) Lipoprotein lipase and acid lipase activity in rabbit brain microvessels. J Lipid Res 20:464-471.

Chui DH, Tanahashi H, Ozawa K, Ikeda S, Checler F, Ueda O, Suzuki H, Araki W, Inoue H, Shirotani K, Takahashi K, Gallyas F, Tabira T (1999) Transgenic mice with Alzheimer presenilin 1 mutations show accelerated neurodegeneration without amyloid plaque formation. Nat Med 5:560-564.

Demeester N, Castro G, Desrumaux C, De Geitere C, Fruchart JC, Santens P, Mulleners E, Engelborghs S, De Deyn PP, Vandekerckhove J, Rosseneu M, Labeur C (2000) Characterization and functional studies of lipoproteins, lipid transfer lipoproteins, and lecithin: cholesterol acyltransferase in CSF of normal individuals and patients with Alzheimer's disease. J Lipid Res 41:963-974.

Deutsch JW, Kelly RB (1981) Lipids of synaptic vesicles: relevance to the mechanism of membrane fusion. Biochemistry 20:378-385.

Eckel RH (1989) Lipoprotein lipase. A multifunctional enzyme relevant to common metabolic diseases. N Engl J Med 320:1060-1068.

Erin AN, Gorbunov NV, Brusovanik VI, Tyurin VA, Prilipko LL (1986) Stabilization of synaptic membranes by alpha-tocopherol against the damaging action of phospholipases. Possible mechanism of biological action of vitamin E. Brain Res 398:85-90.

Fattoretti P, Bertoni-Freddari C, Caselli U, Paoloni R (1995) The effect of vitamin E deficiency on the plasticity of cholinergic synapses: a computerassisted morphometric strudy. Boll Soc Ital Biol Sper 71:119-124.

Ferri P, Cecchini T, Ambrogini P, Betti M, Cuppini R, Del Grande P, Ciaroni S (2006) Alpha-tocopherol affects neuronal plasticity in adult rat dentate gyrus: the possible role of PKCdelta. J Neurobiol 66:793-810.

Goldberg IJ (1996) Lipoprotein lipase and lipolysis: central roles in lipoprotein metabolism and atherogenesis. J Lipid Res 37:693-707.

Goldberg IJ, Soprano DR, Wyatt ML, Vanni TM, Kirchgessner TG, Schotz 
MC (1989) Localization of lipoprotein lipase mRNA in selected rat tissues. J Lipid Res 30:1569-1577.

Goti D, Balazs Z, Panzenboeck U, Hrzenjak A, Reicher H, Wagner E, Zechner R, Malle E, Sattler W (2002) Effects of lipoprotein lipase on uptake and transcytosis of low density lipoprotein (LDL) and LDL-associated $\alpha$-tocopherol in a porcine in vitro blood-brain barrier model. J Biol Chem 277:28537-28544.

Koch S, Donarski N, Goetze K, Kreckel M, Stuerenburg HJ, Buhmann C, Beisiegel U (2001) Characterization of four lipoprotein classes in human cerebrospinal fluid. J Lipid Res 42:1143-1151.

Lang T, Bruns D, Wenzel D, Riedel D, Holroyd P, Thiele C, Jahn R (2001) SNAREs are concentrated in cholesterol-dependent clusters that define docking and fusion sites for exocytosis. EMBO J 20:2202-2213.

Martin TF (2001) PI (4,5)P(2) regulation of surface membrane traffic. Curr Opin Cell Biol 13:493-499.

Michaelson DM, Barkai G, Barenholz Y (1983) Asymmetry of lipid organization in cholinergic synaptic vesicle membranes. Biochem J 211:155-162.

Mitter D, Reisinger C, Hinz B, Hollmann S, Yelamanchili SV, Treiber-Held S, Ohm TG, Herrmann A, Ahnert-Hilger G (2003) The synaptophysin/ synaptobrevin interaction critically depends on the cholesterol content. J Neurochem 84:35-42.

Morris MC, Evans DA, Bienias JL, Tangney CC, Wilson RS (2002) Vitamin $\mathrm{E}$ and cognitive decline in older persons. Arch Neurol 59:1125-1132.

Paradis E, Clement S, Julien P, Ven Murthy MR (2003) Lipoprotein lipase affects the survival and differentiation of neural cells exposed to very low density lipoprotein. J Biol Chem 278:9698-9705.

Paradis E, Julien P, Ven Murthy MR (2004) Requirement for enzymatically active lipoprotein lipase in neuronal differentiation: a site-directed mutagenesis study. Brain Res Dev Brain Res 149:29-37.

Preiss-Landl K, Zimmermann R, Hämmerle G, Zechner R (2002) Lipoprotein lipase: the regulation of tissue specific expression and its role in lipid and energy metabolism. Curr Opin Lipidol 13:471-481.

Rohrbough J, Broadie K (2005) Lipid regulation of the synaptic vesicle cycle. Nat Rev Neurosci 6:139-150.

Ross CJ, Liu G, Kuivenhoven JA, Twisk J, Rip J, van Dop W, Excoffon KJ,
Lewis SM, Kastelein JJ, Hayden MR (2005) Complete rescue of lipoprotein lipase deficient mice by somatic gene transfer of the naturally occurring LPLS447X beneficial mutation. Arterioscler Thromb Vasc Biol 25:2143-2150.

Sarter M, van der Linde A (1987) Vitamin E deprivation in rats: some behavioral and histochemical observations. Neurobiol Aging 8:297-307.

Sattler W, Levak-Frank S, Radner H, Kostner GM, Zechner R (1996) Muscle-specific overexpression of lipoprotein lipase in transgenic mice results in increased $\alpha$-tocopherol levels in skeletal muscle. Biochem 318:15-19.

Sudhof TC (2004) The synaptic vesicle cycle. Annu Rev Neurosci 27:509-547.

Tanemura K, Chui DH, Fukuda T, Murayama M, Park JM, Akagi T, Tatebayashi Y, Miyasaka T, Kimura T, Hashikawa T, Nakano Y, Kudo T, Takeda M, Takashima A (2006) Formation of tau inclusions in knock-in mice with familial Alzheimer disease (FAD) mutation of presenilin 1 (PS1). J Biol Chem 281:5037-5041.

Thiele C, Hannah MJ, Fahrenholz F, Huttner WB (2000) Cholesterol binds to synaptophysin and is required for biogenesis of synaptic vesicles. Nat Cell Biol 2:42-49.

Traber MG, Burton GW, Hughes L, Ingold KU, Hidaka H, Malloy M, Kane J, Hyams J, Kayden HJ (1992) Discrimination between forms of vitamin E by humans with and without genetic abnormalities of lipoprotein metabolism. J Lipid Res 33:1171-1182.

Wenk MR, De Camilli P (2004) Protein-lipid interactions and phosphoinositide metabolism in membrane traffic: insights from vesicle recycling in nerve terminals. Proc Natl Acad Sci U S A 101:8262-8269.

Yacoub LK, Vanni TM, Goldberg IJ (1990) Lipoprotein lipase mRNA in neonatal and adult mouse tissues: comparison of normal and combined lipase deficiency (cld) mice assessed by in situ hybridization. J Lipid Res 31:1845-1852.

Zhang X, Qi R, Xian X, Yang F, Blackstein M, Deng X, Fan J, Ross C, Karasinska J, Hayden MR, Liu G (2008) Spontaneous atherosclerosis in aged LPL-deficient mice with severe hypertriglyceridemia on a normal chow diet. Circ Res 102:250-256. 